\title{
The cross-reactivity of the enterovirus 71 to human brain tissue and identification of the cross-reactivity related fragments
}

\author{
Chun Shi Jia', Jiang Ning Liu', Wan Bo Li', Chun Mei Ma', Shu Zhu Lin', Yi Hao', Xue Zhong Gao², Xiao Lin Liu², \\ Yan Feng $\mathrm{Xu}^{1}$, Lian Feng Zhang ${ }^{1}$, Chuan Qin $^{1^{*}}$
}

\begin{abstract}
Background: EV71 occasionally cause a series of severe neurological symptoms, including aseptic meningitis, encephalitis, and poliomyelitis-like paralysis. However, the neurological destruction mechanism was remained to be clarified. This study described the cross reaction between EV71 induced IgG and human brain tissue.

Results: Cross reaction of the IgG from 30 EV71 infected patients' sera to human tissues of cerebra was observed, which suggested that some EV71 antigens could induce IgG cross-reactivity to human cerebra. To identify the regions of EV71 virus that containing above antigens, the polypeptide of virus was divided into 19 peptides by expression in prokaryotes cell. Mouse anti-sera of these peptides was prepared and applied in immunohistochemical staining with human adult and fetus brain tissue, respectively. The result indicated the 19 peptides can be classified into three groups: strong cross-reactivity, weak cross-reactivity and no cross-reactivity with human brain tissue according the cross reaction activity. Then, the increased Blood Brain Barrier (BBB) permeability and permits IgG entry in neonatal mice after EV71 infection was determined.
\end{abstract}

Conclusion: EV71 induced lgG could enter BBB and cross-reacted with brain tissue in EV71 infected neonatal mice, and then the peptides of EV71 that could induce cross-reactivity with brain tissue were identified, which should be avoided in future vaccine designing.

\section{Background}

Human enterovirus (EV71) was first described by Schimdit et al. in 1974 [1], which belonging to Picornaviridea family and has a single positive stranded ribonucleic acid (RNA) of about 7,500 nucleotides [2,3]. There have 13 large and small reported outbreaks of EV71 throughout the world since then, which main leads to high prevalence of hand, foot and mouth disease (HFMD) in infants and children under 6 years old [4-6]. In past decades, countries in the Asia-Pacific region have experienced an increased occurrence of EV71 associated HMFD outbreak [7-11]. Most of EV71 infection are benign and selflimited in nature, however, EV71 infection has been

\footnotetext{
* Correspondence: Qinchuan@pumc.edu.cn

'Key Laboratory of Human Diseases Comparative Medicine, Ministry of Health, Institute of Laboratory Animal Science, Chinese Academy of Medical Sciences (CAMS) \& Comparative Medicine Centre, Peking Union Medical Collage (PUMC), Chao Yang Strict, Pan Jia Yuan Nan Li No.5, Beijing 100021, PR China
}

(c) $2010 \mathrm{Jia}$ et al; licensee BioMed Central Ltd. This is an Open Access article distributed under the terms of the Creative Commons Attribution License (http://creativecommons.org/licenses/by/2.0), which permits unrestricted use, distribution, and reproduction in any medium, provided the original work is properly cited. reported to cause neurological disease manifesting as aseptic meningitis, encephalitis or poliomyelitis-like acute flaccid paralysis, and neurological originated pulmonary edema or hemorrhage was the main reason of lethal symptom $[4,12]$. The central nervous system (CNS) injury dependent EV71 neuropathology is supposed as the main reason kills neuron and then lead to subsequent neurological destruction [4,13-18]. Although a certain numbers of research work have been carried out, as no abundant virus titer was detected in the CNS during EV71 challenge in mice model, meanwhile, the attenuated EV71 strain can still induce weak neurological symptoms in monkey, the detailed mechanism of CNS dysfunction is remained to be clarified $[15,19]$.

EV71 virus infection was reported to increase the permeability of BBB [20,21]. However, as enter of virus into cranial was dependent on a retrograde axonal neuronal transmission way, the increased permeability in BBB was presumed not essential for virus through BBB. As 
described in Epilepsy, self immunity caused by the common antigens between virus and cell receptors lead to neuron injury, in which the central nervous system (CNS) is attacked by the immune system and that provide a inspiration for the possible new way during the pathology of EV71 infection study [22].

In current study, the sera isolated from EV71 infected patients were indicated to cross reaction with the human tissues of cerebrum by immunohistochemical staining and then the regions can elicit cross-reactivity with normal brain tissues were identified.

\section{Results}

\section{Cross reaction of the IgG from EV71 infected patients} sera to human tissues of cerebra

A large outbreak of HFMD in infants and children was happened in Fuyang region of China in the spring of $2008[23,24]$. Thirty sera from children with HFMD was collected, who was infected with EV71 after RT-PCR diagnosis the specimen of throat swab, and the presence of EV71 induced antibody (both IgM and IgG) in all the thirty sera was verified by ELISA (data not show). As neurological pulmonary edema or hemorrhage was the main reason of lethal symptom $[25,26]$, and our inactivated virus vaccine showed neurological virulence while applied in primates test (date not show), the 30 sera from EV71 infected patients were used as primary anti-sera to perform the immunohistochemical staining with adult human tissues of cerebra (Fig. 1). The normal sera from five donors (four children and one adult) were used as negative control, in which the anti- EV71 IgG and IgM was free with ELISA analysis. The human tissues of cerebra was not stained obviously with negative control sera (Fig. 1B-F), while the human tissues of cerebra was stained on the neuron glial cell, neuron and stroma by the patients sera (Fig. 1G-L). The positive staining was observed in all of the 30 sera from EV71 infected patients and $86 \%$ of the 30 sera showed cross reaction with 10 $40 \%$ stained cells (Table 1 ). To exclude the interference of remained ingredients in sera, the IgG fraction in three sera samples were purified and used as primary antibodies in immunohistochemical staining with human brain tissues, and the results were consistent to sera's experiment in neuron glial cell and neuron, but not in stroma (Fig. 1M-O). These results indicated the presence of specific IgG in the EV71 infected patient sera having the cross-reactivity activity to human cerebra and suggested that some EV71 antigens could induce cross-reactivity to human cerebra. The expression and purification of the peptides disassembled from EV71To identify the regions of EV71 virus that can induce antibodies binding with human brain tissue, the genome of EV71 was divided into 22 regions in sequence, which encode peptides between $22 \sim 156$ amino acids (Fig. 2A), and the nearby fragments in a functional gene have 12 to 39 bp overlap to avoid the miss of epitope. EV71 of Fuyang-0805 strain isolated from Anhui province of China was used as the templates for primers designing and RT-PCR (see Additional file 1). Targeted cDNA fragments were cloned into pETIS vector modified from pET28a (+) (Fig. 2B), and then the fusion peptides with six histidine residues tag were over-expressed. Nineteen of the 22 targeted cDNA fragments were synthesized in insoluble inclusion body forms by $E$. coli, but three of them, $\mathrm{P}_{1013-1111}, \mathrm{P}_{1112-1201}$ and $\mathrm{P}_{1527-1548}$, were failed to expression in this bacteria strain. After Ni-HTA purification, all of the 19 peptides were purified to a purity of $95 \%$ (see Additional file 2).

\section{Identification of EV71 fragments inducing cross-reactivity to human brain tissue}

The 19 purified peptides were applied to immunize the 6 weeks female ICR mice according polyclonal antibody preparation procedure described in the Method. The sera of immunized mice were collected, and the titers of IgG against EV71 in the sera were determined by ELISA respectively (Table 2). No lesions in any of the brain tissues of immunized mice were observed (data not show), then, the 19 sera were applied in immunohistochemical staining to identify which sera have cross reaction with human adult and fetus brain tissues, respectively (Fig. 3). The anti-sera of $\mathrm{P}_{230-323}, \mathrm{P}_{646-755}, \mathrm{P}_{857-1012}$ and $\mathrm{P}_{1329-1440}$ showed strong staining with neuron plasma in both adult human cerebra and fetus medulla compared with the negative control (Fig. 3A-D). The anti-sera of $\mathrm{P}_{1-69}$, $\mathrm{P}_{324-443}, \mathrm{P}_{444-565}, \mathrm{P}_{566-665}, \mathrm{P}_{746-876}, \mathrm{P}_{1441-1526}, \mathrm{P}_{1549-1668}$, $\mathrm{P}_{1732-1851}, \mathrm{P}_{1952-2071}$ and $\mathrm{P}_{2072-2193}$ showed weaker staining with the human brain tissues than the anti-sera of $\mathrm{P}_{230-323}$, $\mathrm{P}_{646-755}, \mathrm{P}_{857-1012}$ and $\mathrm{P}_{1329-1440}$ (Fig. 3E and 3F). The antisera of $\mathrm{P}_{70-159}, \mathrm{P}_{140-249}, \mathrm{P}_{1197-1338}, \mathrm{P}_{1649-1731}, \mathrm{P}_{1843-1951}$ did not show staining with both the adult human cerebra and fetus medulla sections (Fig. $3 \mathrm{G}$ and $3 \mathrm{H}$ ). This result indicated that the peptides of $\mathrm{P}_{230-323}, \mathrm{P}_{646-755}, \mathrm{P}_{857-1012}$ and $\mathrm{P}_{1329-1440}$ could induce strong IgG cross-reactivity to human brain tissue. The significant of cross reactivity was not relevant to the specific IgG titer induced by individual peptides (Table 2), which indicated the cross reactivity was a specific IgG behavior rather than an antibody dose dependent artifact.

\section{EV71 infection increased BBB permeability and IgG transport}

An EV71 mice infection model was build in our laboratory (unpublished data), neonatal mice were intraperitoneal infected with $5 \times 10^{5}$ TCID $_{50}$ virus within $24 \mathrm{~h}$ after birth, the virus replication was detected in brain, lung, small intestine and skeletal muscle at $5 \mathrm{dpi}$ by Real-time PCR and virus titer determination in RD cell, respectively. Then, the virus locations in these tissues 

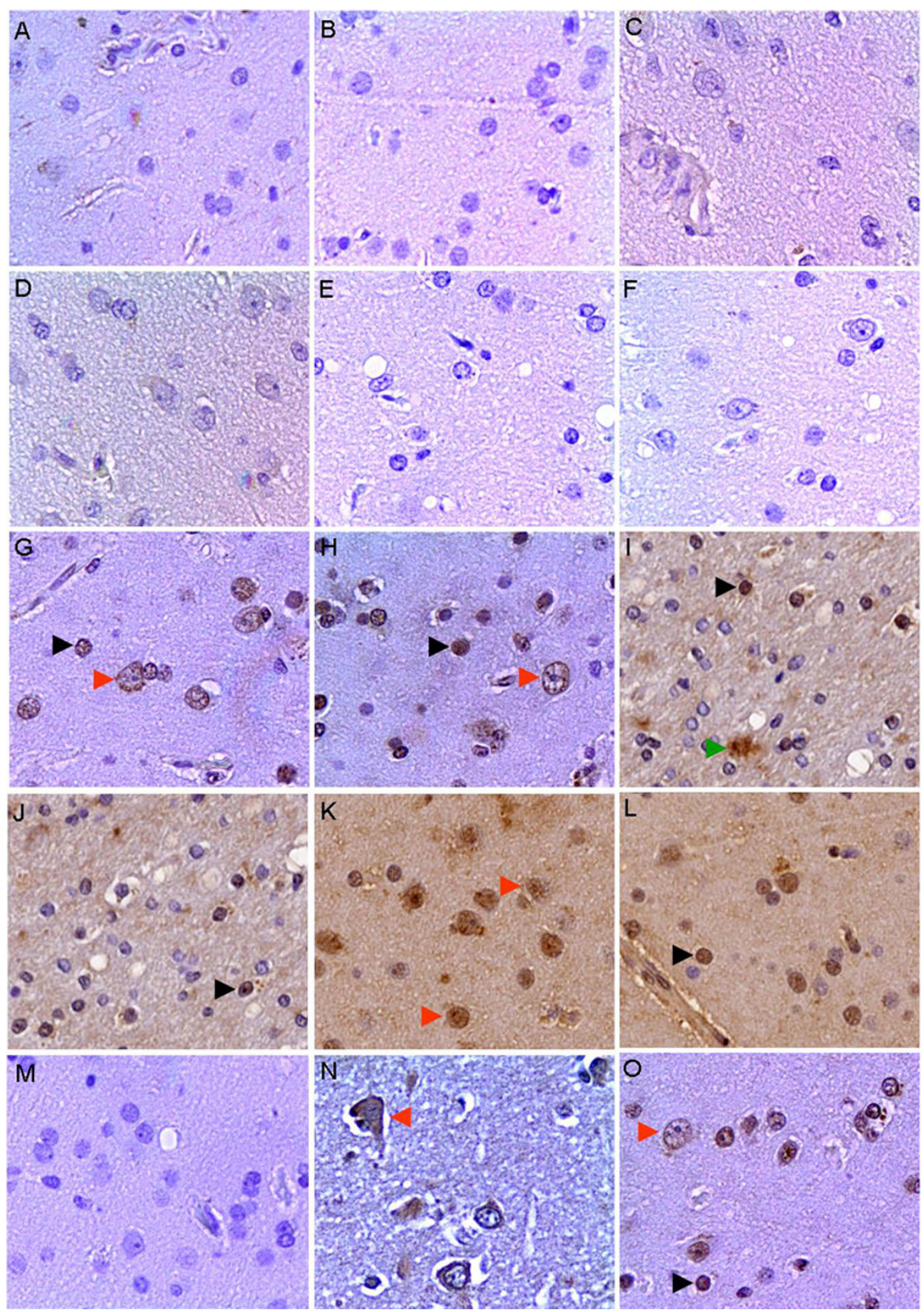

Figure 1 Cross reaction of the IgG from EV71 infected patients' sera with human tissues of cerebra. The serum was replaced by PBS buffer as blank control (a), and naive sera from five health donors were used as negative control (b-f). The sera of CNILASTB-16 (g), CNILASTB-19 (h), CNILASTB-1 (i), CNILASTB-2 (j), CNILASTB-4 (k) and CNILASTB-9 (I) were used as primary antibodies in immunohistochemical staining with the cerebra of adult. The IgG fraction in the sera of NORMAL-1 (m), CNILASTB-12 ( $\mathrm{n}$ ) and CNILASTB-4 (o) were used as primary antibodies in immunohistochemical staining with the cerebra of adult to exclude the interference of the remained ingredients in sera. The stained glial cell, stroma and neuron were denoted with black, green and red arrows respectively $(\times 200)$. 
Table 1 Evaluation the immunohistochemical staining results of patients' sera to adult human cerebra

\begin{tabular}{|c|c|c|c|}
\hline $\begin{array}{l}\text { Sera no/human } \\
\text { sex/age }\end{array}$ & Clinical features/Diagnosis & $\begin{array}{c}\text { Day of sera } \\
\text { collection after } \\
\text { onset }\end{array}$ & $\begin{array}{l}\text { Evaluation } \\
\text { score }\end{array}$ \\
\hline NORMAL-1/F/1.5 & $\mathrm{NO}$ & - & - \\
\hline NORMAL-2/M/3.5 & NO & - & - \\
\hline NORMAL-3/F//4 & NO & - & - \\
\hline NORMAL-4/M/2.6 & NO & - & - \\
\hline NORMAL-5/F/23 & NO & - & - \\
\hline CNILASTB-1/M/1.5 & Fever, HMFD/Brain stem encephalitis & 1 & +++ \\
\hline CNILASTB-2/F/2.8 & Fever, irritability, myoclonus, HFMS/Brain stem encephalitis & 1 & ++ \\
\hline CNILASTB-3/M/3.6 & Fever, myoclonus, HMFD/Brain stem encephalitis & 1 & +++ \\
\hline CNILASTB-4/F/4.5 & Fever, irritability, HMFD/Brain stem encephalitis & 3 & ++++ \\
\hline CNILASTB-5/M/2.5 & HMFD/- & 0 & ++ \\
\hline CNILASTB-6/M/1.8 & HMFD/- & 0 & ++ \\
\hline CNILASTB-7/M/1.5 & Fever, vomiting, irritability, HMFD/Brain stem encephalitis & 0 & +++ \\
\hline CNILASTB-8/F/2.4 & HMFD/- & 0 & ++ \\
\hline CNILASTB-9/F/2.5 & Fever, vomiting, motor weakness/Aseptic meningitis & 3 & +++ \\
\hline CNILASTB-10/M/1.5 & Fever, vomiting, HMFD/Brain stem encephalitis & 1 & +++ \\
\hline CNILASTB-11/M/2.2 & Fever, irritability, myoclonus, HMFD/Brain stem encephalitis & 2 & +++ \\
\hline CNILASTB-12/M/1.6 & HMFD/- & 0 & + \\
\hline CNILASTB-13/M/1.2 & HMFD/- & 0 & ++ \\
\hline CNILASTB-14/M/1.8 & Fever, irritability,/Brain stem encephalitis & 0 & ++ \\
\hline CNILASTB-15/F/2.6 & $\begin{array}{l}\text { Fever, lethargy, ataxia, HFMS/Brain stem } \\
\text { encephalitis, neurogenic shock, pulmonary edema }\end{array}$ & 0 & ++++ \\
\hline CNILASTB-16/M/4.6 & $\mathrm{HFMD/-}$ & 0 & + \\
\hline CNILASTB-17/M/5.4 & HFMD/- & 1 & ++ \\
\hline CNILASTB-18/F/3.2 & Fever, vomiting, lethargy, motor weakness/Aseptic meningitis & 1 & +++ \\
\hline CNILASTB-19/F/5.2 & HFMD/- & 2 & + \\
\hline CNILASTB-20/F/5 & Fever, vomiting, lethargy, nystagmus, shock/Brain stem encephalitis, pulmonary edema & 1 & +++ \\
\hline CNILASTB-21/M/3.6 & Fever, vomiting, headache/Aseptic meningitis & 2 & +++ \\
\hline CNILASTB-22/F/3.2 & $\mathrm{HFMD} /-$ & 0 & + \\
\hline CNILASTB-23/F/2.4 & Irritability, lethargy, apathy, myoclonus, HFMS/Aseptic meningitis & 2 & +++ \\
\hline CNILASTB-24/M/1.7 & $\begin{array}{c}\text { Fever, vomiting, lethargy, nystagmus, myoclonus, shock/Brain stem encephalitis, } \\
\text { neurogenic shock, pulmonary edema }\end{array}$ & 2 & +++ \\
\hline CNILASTB-25/M/3.4 & HFMD/- & 1 & ++ \\
\hline CNILASTB-26/F/4.6 & HFMD/- & 1 & ++ \\
\hline CNILASTB-27/F/2.8 & Fever, vomiting, headache, irritability, HMFD/Aseptic meningitis & 1 & ++ \\
\hline CNILASTB-28/M/3 & Fever, lethargy, myoclonus, shock/Aseptic meningitis & 2 & +++ \\
\hline CNILASTB-29/F/2 & $\mathrm{HFMD/-}$ & 2 & ++ \\
\hline CNILASTB-30/M/3.2 & $\begin{array}{c}\text { Fever, vomiting, headache, myoclonus, HFMS/Brain stem } \\
\text { encephalitis }\end{array}$ & 1 & +++ \\
\hline
\end{tabular}

- No obvious staining was observed;

$+0 \sim 10 \%$ cell was stained;

$++11 \% \sim 20 \%$ cell was stained;

$+++21 \% \sim 30 \%$ cell was stained;

$++++31 \% \sim 40 \%$ cell was stained.

were verified by immunohistochemical staining with a monoclonal antibody of EV71 (Millipore). Large area of neuron apoptosis was observed in cerebrum and medulla of brain tissue. In small intestine, intestinal villus interstitial edema and epithelial cell vacuolar degeneration were observed. In skeletal muscle, inflammation, muscle fiber degeneration and necrosis were scarcely observed. However, although virus replication and virus antigens were detected in lung, no obvious lesion was observed in this organ. As no lesions in all the brain tissues of immunized adult mice were observed, we studied the BBB permeability of neonatal mice upon EV71 infection. Naive or EV71 induced IgG was intravenous injected into the neonatal mice upon EV71 infection or 


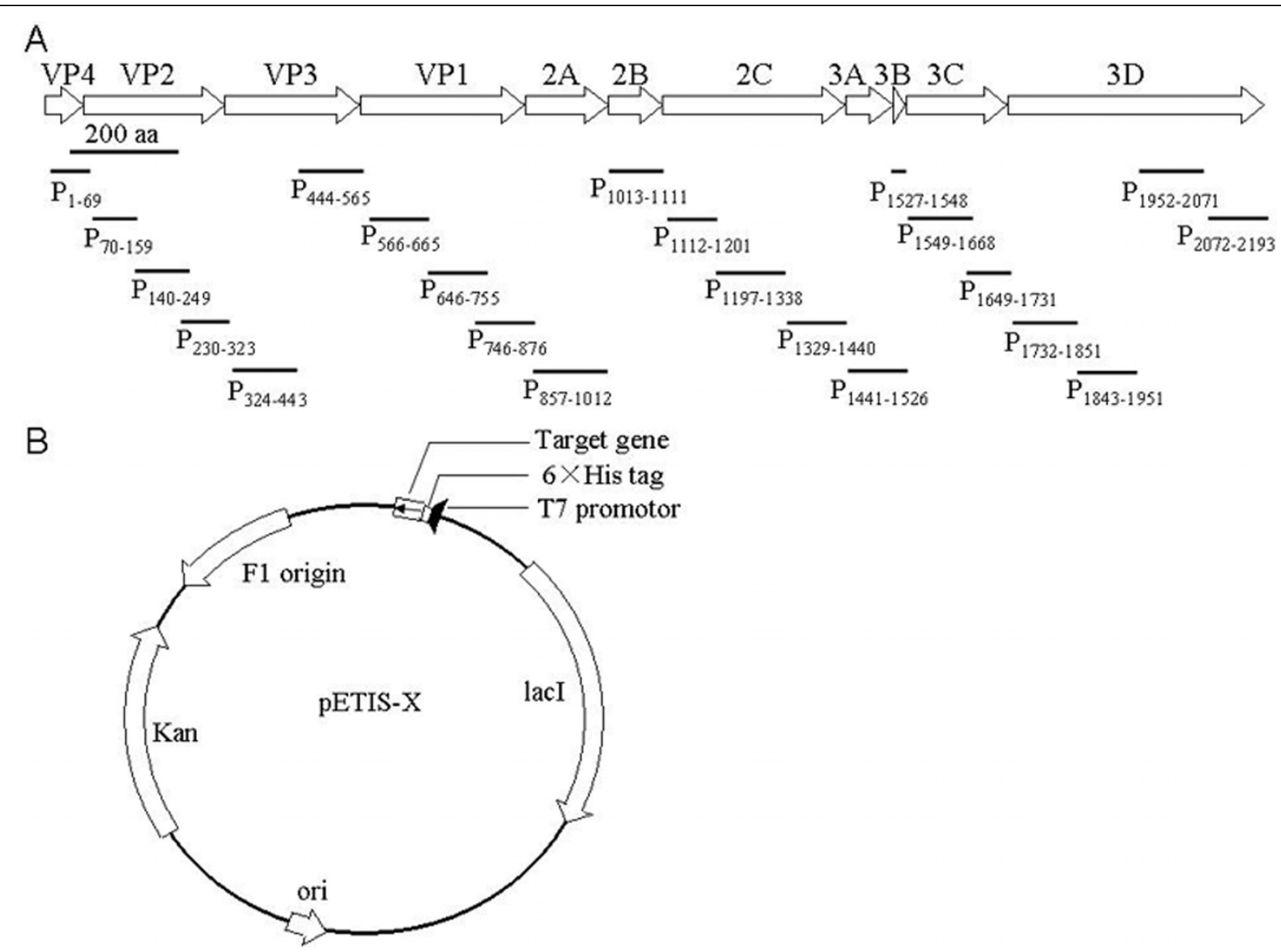

Figure 2 Diagrams of divided 22 peptides from EV71 and expression construction. The position and length of 22 peptides divided from EV71 (a) and expression constructs for 22 peptides (b) were diagramed.

not, respectively. And the detection results were shown in Fig. 4, both weak staining sites were observed in EV71 infected mice brain tissues after naive or EV71 induced IgG injection (Fig. 4B and 4D), while the staining was scarcely observed in normal mice brain tissue after IgG injection (Fig. 4A and 4C). And the intracranial IgG showed a weak diffused distribution in the brain tissue of EV71 infected mice, which indicated that compared to normal neonatal mice, the BBB permeability of EV71 infected mice was increased and permits both the naïve IgG and EV71 induced IgG entry.

\section{Discussion}

The HFMD occasionally causes a series of severe neurological symptoms, including aseptic meningitis, encephalitis, poliomyelitis-like paralysis and neurological originated pulmonary edema or hemorrhage [25,27-29], especially the latter was the main reason of lethal symptom in infants and children [4,12]. Previous study suggested the neuropathological symptom was caused by the EV71 infection in CNS [30-34]. However, Chen CS et al. reported that although the infection led to a persistent viremia and a transient increase in BBB permeability, but only low levels of virus could be detected in the mice brain [15], and Arita $M$ et al. reported that the monkeys vaccinated with an attenuated EV71 showed the broad range of CNS tissues inflammation related to the peak stages of IgM and IgG producing, but without the efficient virus replication [19]. Those results suggested that the pathogenesis of neurological symptoms with HFMD may have more mechanisms.

We find that all of the tested EV71 infected patients' sera were presence of IgG to cross-react with health human brain tissues (Fig. 1), which suggested that a potential cross-reactivity of EV71 with human brain tissues. To identify the fragments of EV71 that induce cross-reactivity to human brain tissue, the whole genome of virus was divided into 22 fragments sequentially. The 19 of 22 fragments were successfully expressed and purified, however, 3 fragments was failed to expressed in prokaryote environment and those were given up. For cross-reactivity assay, the polyclonal mouse anti-sera 
Table 2 ELISA determines the titers of sera from immunized mice to peptides and virus

\begin{tabular}{ccc}
\hline & \multicolumn{2}{c}{ OD $_{450}$ Value } \\
\cline { 2 - 3 } Peptide name & Peptides $^{\mathbf{a}}$ & Virus $^{\mathbf{b}}$ \\
\hline$P_{1-69}$ & $1.231 \pm 0.114$ & $0.231 \pm 0.034$ \\
$P_{70-159}$ & $1.781 \pm 0.221$ & $0.446 \pm 0.041$ \\
$P_{140-249}$ & $1.940 \pm 0.234$ & $0.557 \pm 0.071$ \\
$P_{230-323}$ & $1.126 \pm 0.167$ & $0.359 \pm 0.053$ \\
$P_{324-443}$ & $1.125 \pm 0.138$ & $0.678 \pm 0.072$ \\
$P_{444-565}$ & $1.864 \pm 0.245$ & $1.246 \pm 0.116$ \\
$P_{566-665}$ & $2.142 \pm 0.175$ & $1.648 \pm 0.157$ \\
$P_{646-755}$ & $0.948 \pm 0.056$ & $0.467 \pm 0.067$ \\
$P_{746-876}$ & $1.084 \pm 0.097$ & $0.647 \pm 0.064$ \\
$P_{857-1012}$ & $1.562 \pm 0.149$ & $0.169 \pm 0.022$ \\
$P_{1197-1338}$ & $2.214 \pm 0.195$ & $0.328 \pm 0.016$ \\
$P_{1329-1440}$ & $1.194 \pm 0.134$ & $0.294 \pm 0.008$ \\
$P_{1441-1526}$ & $1.162 \pm 0.158$ & $0.175 \pm 0.006$ \\
$P_{1549-1668}$ & $0.955 \pm 0.037$ & $0.186 \pm 0.011$ \\
$P_{1649-1731}$ & $1.556 \pm 0.115$ & $0.268 \pm 0.018$ \\
$P_{1732-1851}$ & $1.678 \pm 0.160$ & $0.327 \pm 0.020$ \\
$P_{1843-1951}$ & $1.966 \pm 0.138$ & $0.267 \pm 0.013$ \\
$P_{1952-2071}$ & $1.763 \pm 0.129$ & $0.291 \pm 0.026$ \\
$P_{2072-2193}$ & $1.567 \pm 0.146$ & $0.488 \pm 0.038$ \\
\hline
\end{tabular}

${ }^{a}$ the sera were used to determine the titer to its self peptide in a dilution 1:50,000.

${ }^{b}$ the sera were used to determine the titer to virus in a dilution 1:1,000. Values represent means \pm SD of three independent experiments.

against the 19 peptides were prepared and applied in the immunohistochemical analysis with the adult human cerebra and fetus medulla. The results indicated the 19 peptides can be divided into three groups according the cross reaction activity. There were 4 peptides showed strong cross-reactivity with human brain tissues. There were 10 peptides showed weak cross-reactivity with human brain tissues and there were 5 peptides showed no cross-reactivity with human brain tissues. Sera of patients and the strong cross-reactivity peptides showed a similar pattern on the staining of neuron of the human brain tissues (Fig. 1 and 3). These suggested the strong cross-reactivity peptides were potential common antigens of the EV71 with human brain tissue, however, the brain binding partner of EV71 induced IgG was not identified in this work. The peptides that elicit antibodies can bind to human brain tissue was dispersed in whole proteome of EV71, rather than gathered in one or several structural proteins. So, the potentially self-reaction antibodies would be induced over the whole process of virus infection including virus invasion, propagation and releasing. In previous study, both attenuated and avirulent virus or virus like particles were able to induce significant neutralization antibody, relax the clinical symptoms and reduce mortality rate of laboratory animals upon lethal virus challenge[19,35,36].

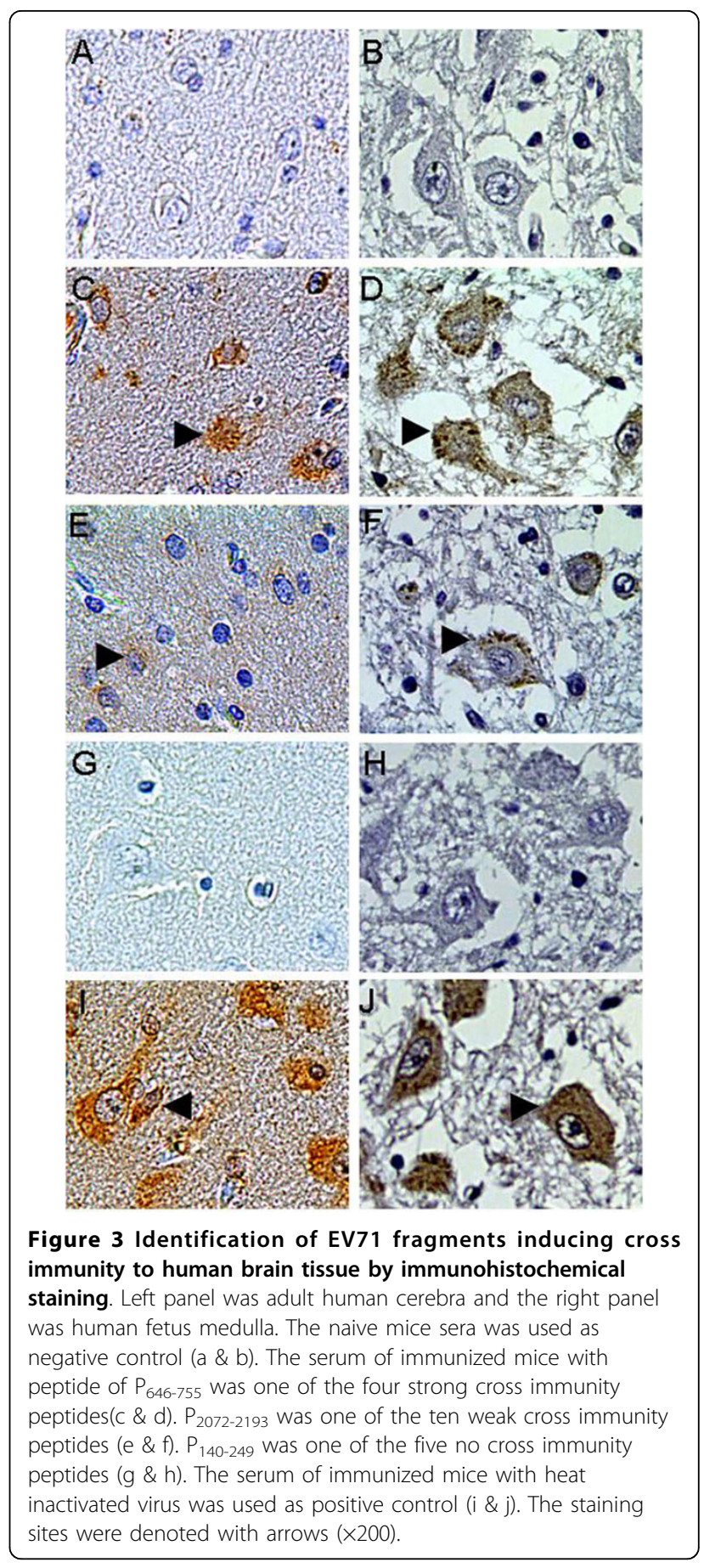

As indicated in cynomolgus monkeys, although an attenuated EV71 strain showed obvious protection activity in vivo, the inoculated monkeys still manifested weak neurological symptom[19]. VP1, located in the surface of virus particles, was thought as the predominant epitope clustering protein, has been broadly used as subunit vaccine to substitute whole virus and elicit significant protection on neonatal animals [37-42]. 

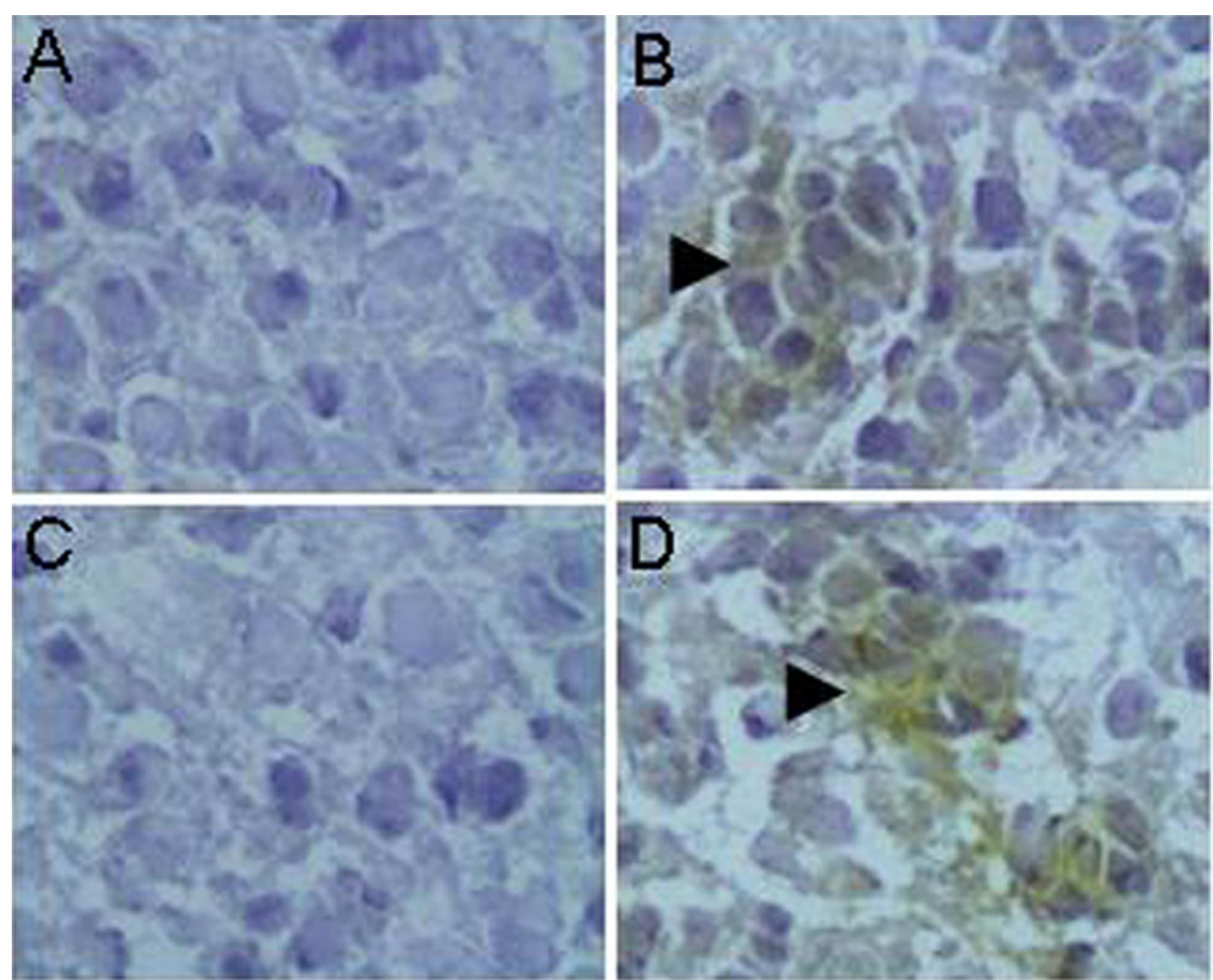

Figure 4 Detection the intracranial IgG in mice after intravenous injection. The normal neonatal mice injected with naive lgG. (a), EV71 infected neonatal mice injected with mice naïv IgG. (b), normal neonatal mice injected with EV71 induced lgG. (c) and EV71 infected neonatal mice injected with EV71 induced lgG.(d) were compared by the immunohistochemical test. The staining sites were denoted with arrows ( $\times 200)$.

However, the IgG induced by $\mathrm{P}_{646-755}$, which belongs to VP1, elicited strong cross-reactivity to human brain tissue, so the neurological safety of whole virus or VP1 protein as vaccine should be concerned before clinical application. Many disease and virus infection, especially the neurological disease can increase the BBB permeability, e.g. stroke, human immunodeficiency virus, Alzheimer's disease, brain cancer, and bacterial infections of the CNS [20,21,43], likewise, the increased BBB permeability after EV71 infection was verified in a mice model [15]. Our result also indicated the increase of BBB permeability after EV71 infection in infant mice and further more, the increase of BBB permeability after EV71 infection could result in the entrance and localization of the IgG into brain tissues. Autoimmune disease was reported in many previous studies, such as celiac disease, sclerosis, encephalitis, Diabetes mellitus [44-48]. As the BBB in infant can be destructed upon EV71 infection[15] and the EV71 can induce cross-reactivity IgG, therefore, whether the intracranial entry of EV71 elicited IgG is one of the mechanisms of neurological pathogeneses in HFMD patients was remained to be clarified in further study. However, the cross reaction fragments of the viruses should be concerned in future vaccine designing.

\section{Conclusion}

In conclusion, this study initially showed the cross-reactivity between EV71 induced IgG and human brain tissue, and the peptides of EV71 that can bring IgG based cross reaction was identified. We observed the increase of BBB permeability in neonatal mice under EV71 infection and the entry of brain cross reactivity IgG, which was supposed play a role in subsequent clinical symptoms.

\section{Material and methods}

\section{Cell and virus}

RD cells (human rhabdomyosarcoma) were maintained in Dulbecco's modified Eagle's medium with 10\% fetal bovine serum [49]. EV71 FuYang stock virus strain (Fuyang-0805), which belongs to C4, the predominant 
genotype in recent outbreaks in Asia (GenBank accession number EU703812) was grown in RD cells as described by He YQ et al. and Lin JY et al [50,51].

The infected cell culture was disrupted by three freeze-thaw cycles, then the cell debris was removed by centrifuged at 3,000 $\mathrm{g}$ for $20 \mathrm{~min}$, the virus was collected by centrifuged at $80,000 \times \mathrm{g}$ for $3 \mathrm{~h}$, and then was ected was pur normal neuron resuspended in phosphate buffered saline (PBS) [36] to prepare the working stocks containing $10^{8} \mathrm{TCID}_{50} / \mathrm{ml}$ [13].

\section{Clone of the EV71 DNA fragments and construction of the expression constructs}

The EV71 genomic RNA was extracted from the culture fluid of infected cells using a High-pure viral RNA purification kit (Qiagen). Reverse transcription-PCR (RTPCR) was performed using a ReverTra-Plus kit (Invitrogen) to clone the full length cDNA [19]. The EV71 cDNA was used as template for peptide coding regions amplification. The primers and associated restriction enzyme sites were subjected in Additional file 1. The cloned fragments were inserted into cloning sites of pETIS vector under the T7 promoter and His tag was added at the $\mathrm{N}$-terminal of the target peptide to form a fusion peptide with His tag. The expression plasmids were verified by sequencing analysis respectively.

\section{Peptide expression and purification}

Escherichia. coli BL21 (DE3) was transformed by the constructed expression plasmids for protein expression. The DE3 bacteria strain was cultured with Luria-Bertani (LB) medium with $50 \mu \mathrm{g} / \mathrm{ml}$ kanamycin at $37^{\circ} \mathrm{C}, 200$ rpm. After the $\mathrm{OD}_{600}$ of culture up to 0.6 , the IPTG was added to a final concentration of $0.5 \mathrm{mM}$ into the medium and cultured for $8 \mathrm{~h}$ at 25 . The bacteria pellet was harvested by centrifugation at $4,000 \times \mathrm{g}$ for 20 min, and the expression of targeted proteins were detected by SDS-PAGE.

Protein purification was performed according to the protocol of Novagen with Ni-HTA resin. Briefly, the bacteria pellet was resuspended in buffer $\mathrm{B}$ ( $8 \mathrm{M}$ urine, $0.1 \mathrm{M}$ sodium phosphate salt, $0.01 \mathrm{M}$ Tris- $\mathrm{HCl}, \mathrm{pH}=$ 8.0) and incubated at $37^{\circ} \mathrm{C}$ for $30 \mathrm{~min}$, the cell debris was removed by centrifuged at $20,000 \times$ g for $20 \mathrm{~min}$. Then the supernatant was loaded onto a Ni-HTA resin column. The column was washed with 10 fold column volumes of washing buffer $\mathrm{C}(8 \mathrm{M}$ urine, $0.1 \mathrm{M}$ sodium phosphate salt, $0.01 \mathrm{M}$ Tris- $\mathrm{HCl}, \mathrm{pH}=6.3)$. The target protein was then eluted with buffer $\mathrm{D}(8 \mathrm{M}$ urine, $0.1 \mathrm{M}$ sodium phosphate salt, $0.01 \mathrm{M}$ Tris- $\mathrm{HCl}, \mathrm{pH}=4.5)$ and dialyzed against $0.9 \% \mathrm{NaCl}$, and then the purity of peptides were detected by SDS-PAGE. The concentration of protein was measured by Bradford method [52].

\section{Immunity}

ICR mice were provided by the Institute of Laboratory Animal Science, Peking Union Medical College. All the mice were bred in an AAALAC-accredited facility and the use of animals was approved by the Animal Care and Use Committee of the Institute of Laboratory Animal Science of Peking Union Medical College (GC09012). The adult mice were used for polyclonal antibody preparation. The peptides were dissolved as $1.0 \mathrm{mg} / \mathrm{ml}$ of each peptide in $0.9 \% \mathrm{NaCl}$ and then formulated with same volume of Freund complete adjuvant (Sigma) according to the manufacturer's instructions. The injected dose of the peptides was $100 \mu \mathrm{l} /$ mouse given through intraperitoneal injection (i.p.). The heat inactivated EV71 were dissolved as $1.0 \times 10^{9} \mathrm{TCID}_{50} / \mathrm{ml}$ in $0.9 \% \mathrm{NaCl}$ and the injected dose of the virus was 100 $\mu \mathrm{l}$ per mouse. One week after the first injection, the animals were boosted at the same dose of peptides or the heat inactivated virus formulated with same volume of Freund incomplete adjuvant (Sigma) through intraperitoneal injection(i.p.) and the mice were reboosted weekly for 2 times.

\section{ELISA}

The levels of specific IgG against EV71 or peptides from the immunized mice or EV71 infected patients were determined by enzyme-linked immunosorbent assay (ELISA). Briefly, microtiter plates were coated with 100 $\mu \mathrm{l}$ of heat inactivated virus $\left(1.0 \times 10^{8} \mathrm{TCID}_{50}\right)$ or peptides $(10 \mu \mathrm{g} / \mathrm{ml})$ in carbonate coating buffer $(15 \mathrm{mM}$ $\mathrm{Na}_{2} \mathrm{CO}_{3}, 35 \mathrm{mM} \mathrm{NaHCO} 3, \mathrm{pH}$ 9.6). The plates were incubated at $4{ }^{\circ} \mathrm{C}$ overnight and then incubated with $1 \%$ BSA in PBS for $2 \mathrm{~h}$ at room temperature to prevent non-specific binding, serial dilutions of test sera were added to each well and incubated for $1 \mathrm{~h}$ at $37^{\circ} \mathrm{C}$, followed by horseradish peroxidase (HRP) conjugated goat anti-mouse IgG (1:5, 000 dilution, Sigma). The reaction was developed by $100 \mu \mathrm{l}$ TMB substrate (3, 3', 5, 5'-etramethylbenzidine), and then terminated by $100 \mu \mathrm{l} 2 \mathrm{M}$ $\mathrm{H}_{2} \mathrm{SO}_{4}$. The optical densities at $450 \mathrm{~nm}$ were determined [38].

\section{Immunohistochemical staining}

The cerebra and medulla of human brain tissues were from an adult and a fetus, who were both died in accidents respectively. The usage of human brain tissues and sera were permitted by Institutional Review Board (IRB) of FuYang people's hospital, where these samples were provided. For immunohistochemical staining, brain sections were deparaffinized with xylene, rehydrated in ethanol, and then treated with $0.25 \%$ trypsin solution with $0.5 \% \mathrm{CaCl}_{2}$ in PBS for $30 \mathrm{~min}$ and incubated in $1 \%$ hydrogen peroxide in methanol to block endogenous 
peroxidase activity followed by incubation with $10 \%$ Block Ace (Sigma) in PBS. The treated sections were incubated with specific serum (1:200 dilution for patients' sera and 1:1000 dilution for mice sera with $0.05 \%$ Triton $\times-100-\mathrm{PBS})$ or purified IgG fraction $(1 \mu \mathrm{g} /$ $\mathrm{ml}$ ) from sera of EV71 infected patients at $4^{\circ} \mathrm{C}$ overnight. The sections were washed three times with PBS and then incubated with HRP-conjugated goat antihuman IgG (for patients' sera, 1:500 dilution, Sigma) or HRP-conjugated goat anti-mouse IgG (for innunized mice sera, $1: 1000$ dilution, Sigma) for $1 \mathrm{~h}$ at $37^{\circ} \mathrm{C}$. The sections were developed with 3-3'diaminobenzidine (DAB) and examined with a light microscope [53].

\section{Intracranial IgG detection}

IgG fraction of sera from EV71 infected patients or immunized mice were purified by Protein A conjugated agarose affinity adsorption column [54]. The mice serum was diluted in 5 volumes loading buffer: $20 \mathrm{mM}$ PBS saline buffer $(\mathrm{pH}, 7.0)$ and loaded on a Protein A agarose affinity adsorption column. Then, after washing by 10 volumes loading buffer, the targeted IgG was eluted by $0.1 \mathrm{M}$ citric acid $(\mathrm{pH}, 3.0)$ and dialysis against PBS buffer overnight at $4^{\circ} \mathrm{C} .10 \mu \mathrm{g}$ IgG were intravenous injected into neonatal mice in 2 days later after EV71 infection, and the mice were sacrificed with barbital anaesthesia in 1 days later, then the brain tissue sections were prepared to detect intracranial IgG [20]. IgG presence in brain sections were detected by immunohistochemical staining with HRP conjugated goat anti mouse secondary Ab (1:5,000, sigma) and developed with 3-3'diaminobenzidine $(\mathrm{DAB})$ and examined with a light microscope.

Additional file 1: SDS-PAGE detects the purified peptides of EV71.

The SDS-PAGE result of peptides $P_{1-69}$ to $P_{2072-2193}$ was shown. The

expression plasmids free E. coli BL21 (DE3) strain was manipulated as the protocol of protein expression and purification of peptides and used as negative control. The purified peptides were detected by $12 \%$ SDS-PAGE and the purified virus was detected by $8 \%$ SDS-PAGE.

Click here for file

[ http://www.biomedcentral.com/content/supplementary/1743-422X-7-47S1.DOC ]

Additional file 2: Primers used in divided polypeptides encoding regions amplification

Click here for file

[ http://www.biomedcentral.com/content/supplementary/1743-422X-7-47S2.DOC]

\section{Acknowledgements}

This work was supported by national sciences and technology major project (2009ZX10004-402).

\section{Author details}

'Key Laboratory of Human Diseases Comparative Medicine, Ministry of Health, Institute of Laboratory Animal Science, Chinese Academy of Medical Sciences (CAMS) \& Comparative Medicine Centre, Peking Union Medical Collage (PUMC), Chao Yang Strict, Pan Jia Yuan Nan Li No.5, Beijing 100021 ,
PR China. ${ }^{2}$ Fuyang People's Hospital, Lu Ci Street No.63, Fu Yang city, An Hul province 236003, PR China.

\section{Authors' contributions}

JCS and LN conducted all experiments except for the

Immunohistochemical staining and draft the manuscript. MCM, HY and XYF performed Immunohistochemical staining. LSZ, GXZ and LXL collected the EV71 infected patients sera. LWB and ZLF designed the experiment and edited the manuscript. QC provided overall supervision, financial support and prepared the final version of the manuscript. All authors read and approved the final manuscript.

\section{Competing interests}

The authors declare that they have no competing interests.

Received: 23 October 2009

Accepted: 22 February 2010 Published: 22 February 2010

\section{References}

1. Schmidt NJ, Lennette EH, Ho HH: An apparently new enterovirus isolated from patients with disease of the central nervous system. $J$ Infect Dis 1974, 129:304-309.

2. Brown BA, Pallansch MA: Complete nucleotide sequence of enterovirus 71 is distinct from poliovirus. Virus Res 1995, 39:195-205.

3. Brown BA, Oberste MS, Alexander JP Jr, Kennett ML, Pallansch MA: Molecular epidemiology and evolution of enterovirus 71 strains isolated from 1970 to 1998. J Virol 1999, 73:9969-9975.

4. Ortner B, Huang CW, Schmid D, Mutz I, Wewalka G, Allerberger F, Yang JY, Huemer HP: Epidemiology of enterovirus types causing neurological disease in Austria 1999-2007: detection of clusters of echovirus 30 and enterovirus 71 and analysis of prevalent genotypes. J Med Virol 2009, 81:317-324.

5. Fowlkes AL, Honarmand S, Glaser C, Yagi S, Schnurr D, Oberste MS, Anderson L, Pallansch MA, Khetsuriani N: Enterovirus-associated encephalitis in the California encephalitis project, 1998-2005. J Infect Dis 2008, 198:1685-1691.

6. Diedrich S, Weinbrecht A, Schreier E: Seroprevalence and molecular epidemiology of enterovirus 71 in Germany. Arch Virol 2009, 154:1139-1142.

7. Mizuta K, Abiko C, Murata T, Matsuzaki Y, Itagaki T, Sanjoh K, Sakamoto M, Hongo S, Murayama S, Hayasaka K: Frequent importation of enterovirus 71 from surrounding countries into the local community of Yamagata, Japan, between 1998 and 2003. J Clin Microbiol 2005, 43:6171-6175.

8. Gau SS, Chang LY, Huang LM, Fan TY, Wu YY, Lin TY: Attention-deficit/ hyperactivity-related symptoms among children with enterovirus 71 infection of the central nervous system. Pediatrics 2008, 122:e452-458.

9. Lin YW, Wang SW, Tung YY, Chen SH: Enterovirus 71 Infection of Human Dendritic Cells. Exp Biol Med (Maywood) 2009.

10. Zhu JP, Xu ZG, Chen H, Zhang X, Fan DY, Wang J: Primary detection of pathogen from children with hand, foot, and mouth disease in Beijing, 2007. Bing Du Xue Bao 2009, 25:23-28.

11. Ding NZ, Wang XM, Sun SW, Song Q, Li SN, He CQ: Appearance of mosaic enterovirus 71 in the 2008 outbreak of China. Virus Res 2009.

12. Lin YW, Chang KC, Kao CM, Chang SP, Tung YY, Chen SH: Lymphocyte and antibody responses reduce enterovirus 71 lethality in mice by decreasing tissue viral loads. J Virol 2009, 83:6477-6483.

13. Wang YF, Chou CT, Lei HY, Liu CC, Wang SM, Yan JJ, Su IJ, Wang JR, Yeh TM, Chen SH, Yu CK: A mouse-adapted enterovirus 71 strain causes neurological disease in mice after oral infection. J Virol 2004, 78:7916-7924.

14. Nishimura Y, Shimojima M, Tano Y, Miyamura T, Wakita T, Shimizu H: Human P-selectin glycoprotein ligand-1 is a functional receptor for enterovirus 71. Nat Med 2009, 15:794-797.

15. Chen CS, Yao YC, Lin SC, Lee YP, Wang YF, Wang JR, Liu CC, Lei HY, Yu CK: Retrograde axonal transport: a major transmission route of enterovirus 71 in mice. J Virol 2007, 81:8996-9003.

16. Chen YC, Yu CK, Wang YF, Liu CC, Su IJ, Lei HY: A murine oral enterovirus 71 infection model with central nervous system involvement. J Gen Virol 2004, 85:69-77.

17. Nagata N, Iwasaki T, Ami Y, Tano Y, Harashima A, Suzaki Y, Sato Y, Hasegawa H, Sata T, Miyamura T, Shimizu H: Differential localization of 
neurons susceptible to enterovirus 71 and poliovirus type 1 in the central nervous system of cynomolgus monkeys after intravenous inoculation. J Gen Virol 2004, 85:2981-2989.

18. Nagata N, Shimizu H, Ami Y, Tano $Y$, Harashima A, Suzaki $Y$, Sato $Y$, Miyamura T, Sata T, Iwasaki T: Pyramidal and extrapyramidal involvement in experimental infection of cynomolgus monkeys with enterovirus 71. J Med Virol 2002, 67:207-216.

19. Arita M, Nagata N, Iwata N, Ami Y, Suzaki Y, Mizuta K, Iwasaki T, Sata T, Wakita T, Shimizu H: An attenuated strain of enterovirus 71 belonging to genotype a showed a broad spectrum of antigenicity with attenuated neurovirulence in cynomolgus monkeys. J Virol 2007, 81:9386-9395.

20. Wang $\mathrm{H}$, Sun J, Goldstein $\mathrm{H}$ : Human immunodeficiency virus type 1 infection increases the in vivo capacity of peripheral monocytes to cross the blood-brain barrier into the brain and the in vivo sensitivity of the blood-brain barrier to disruption by lipopolysaccharide. J Virol 2008, 82:7591-7600.

21. Bowman GL, Kaye JA, Moore M, Waichunas D, Carlson NE, Quinn JF: Bloodbrain barrier impairment in Alzheimer disease: stability and functional significance. Neurology 2007, 68:1809-1814.

22. Ganor $Y$, Goldberg-Stern $H$, Amrom D, Lerman-Sagie T, Teichberg VI, Pelled D, Futerman AH, Zeev BB, Freilinger M, Verheulpen D, et al: Autoimmune epilepsy: some epilepsy patients harbor autoantibodies to glutamate receptors and dsDNA on both sides of the blood-brain barrier, which may kill neurons and decrease in brain fluids after hemispherotomy. Clin Dev Immunol 2004, 11:241-252.

23. Wu Z, Yang F, Zhao R, Zhao L, Guo D, Jin Q: Identification of small interfering RNAs which inhibit the replication of several Enterovirus 71 strains in China. J Virol Methods 2009, 159:233-238.

24. Yang Y, Wang H, Du J, Zhao XS, Gong EC, Gao ZF, Zheng J: Molecular confirmation of enterovirus type 71 infection: a post-mortem study of two cases. Zhonghua Bing Li Xue Za Zhi 2009, 38:258-262.

25. Chang LY, Lin TY, Hsu KH, Huang YC, Lin KL, Hsueh C, Shih SR, Ning HC Hwang MS, Wang HS, Lee CY: Clinical features and risk factors of pulmonary oedema after enterovirus-71-related hand, foot, and mouth disease. Lancet 1999, 354:1682-1686.

26. Fujimoto T, Chikahira M, Yoshida S, Ebira H, Hasegawa A, Totsuka A Nishio O: Outbreak of central nervous system disease associated with hand, foot, and mouth disease in Japan during the summer of 2000: detection and molecular epidemiology of enterovirus 71. Microbiol Immunol 2002, 46:621-627.

27. Ang LW, Koh BK, Chan KP, Chua LT, James L, Goh KT: Epidemiology and control of hand, foot and mouth disease in Singapore, 2001-2007. Ann Acad Med Singapore 2009, 38:106-112.

28. Chang $L Y, H$ sia $S H, W u C T$, Huang $Y C$, Lin $K L$, Fang TY, Lin TY: Outcome of enterovirus 71 infections with or without stage-based management: 1998 to 2002. Pediatr Infect Dis J 2004, 23:327-332.

29. Chang LY, Lee CY, Kao CL, Fang TY, Lu CY, Lee PI, Huang LM: Hand, foot and mouth disease complicated with central nervous system involvement in Taiwan in 1980-1981. J Formos Med Assoc 2007, 106:173-176.

30. Chang LY, Huang LM, Gau SS, Wu YY, Hsia SH, Fan TY, Lin KL, Huang YC, Lu CY, Lin TY: Neurodevelopment and cognition in children after enterovirus 71 infection. N Engl J Med 2007, 356:1226-1234.

31. Chen CY, Chang YC, Huang CC, Lui CC, Lee KW, Huang SC: Acute flaccid paralysis in infants and young children with enterovirus 71 infection: MR imaging findings and clinical correlates. AJNR Am J Neuroradiol 2001, 22:200-205.

32. Huang CC: Neurologic complications of enterovirus 71 infection in children: lessons from this Taiwan epidemic. Acta Paediatr Taiwan 2001, 42:5-7.

33. Tyler KL: Emerging viral infections of the central nervous system: part 1. Arch Neurol 2009, 66:939-948.

34. Wong KT, Munisamy B, Ong KC, Kojima H, Noriyo N, Chua KB, Ong BB, Nagashima $\mathrm{K}$ : The distribution of inflammation and virus in human enterovirus 71 encephalomyelitis suggests possible viral spread by neural pathways. J Neuropathol Exp Neurol 2008, 67:162-169.

35. Wu TC, Wang YF, Lee YP, Wang JR, Liu CC, Wang SM, Lei HY, Su IJ, Yu CK Immunity to avirulent enterovirus 71 and coxsackie A16 virus protects against enterovirus 71 infection in mice. J Virol 2007, 81:10310-10315.

36. Chung YC, Ho MS, Wu JC, Chen WJ, Huang JH, Chou ST, Hu YC: Immunization with virus-like particles of enterovirus 71 elicits potent immune responses and protects mice against lethal challenge. Vaccine 2008, 26:1855-1862.

37. Zhou BP, Liu WL, Xie JJ, Chen XC, Xu LM, Tan Y, Liu YX, Yang GL: Expression of recombinant VP1 protein of enterovirus 71 and development of serological assay for detection of EV71 infection. Zhonghua Shi Yan He Lin Chuang Bing Du Xue Za Zhi 2008, 22:492-494.

38. Chen HL, Huang JY, Chu TW, Tsai TC, Hung CM, Lin CC, Liu FC, Wang LC, Chen YJ, Lin MF, Chen CM: Expression of VP1 protein in the milk of transgenic mice: a potential oral vaccine protects against enterovirus 71 infection. Vaccine 2008, 26:2882-2889.

39. Foo DG, Ang RX, Alonso S, Chow VT, Quak SH, Poh CL: Identification of immunodominant VP1 linear epitope of enterovirus 71 (EV71) using synthetic peptides for detecting human anti-EV71 lgG antibodies in Western blots. Clin Microbiol Infect 2008, 14:286-288.

40. Sivasamugham LA, Cardosa MJ, Tan WS, Yusoff K: Recombinant Newcastle Disease virus capsids displaying enterovirus 71 VP1 fragment induce a strong immune response in rabbits. J Med Virol 2006, 78:1096-1104.

41. Chiu CH, Chu C, He CC, Lin TY: Protection of neonatal mice from lethal enterovirus 71 infection by maternal immunization with attenuated Salmonella enterica serovar Typhimurium expressing VP1 of enterovirus 71. Microbes Infect 2006, 8:1671-1678.

42. Chen HF, Chang MH, Chiang BL, Jeng ST: Oral immunization of mice using transgenic tomato fruit expressing VP1 protein from enterovirus 71. Vaccine 2006, 24:2944-2951.

43. Olsen AL, Morrey JD, Smee DF, Sidwell RW: Correlation between breakdown of the blood-brain barrier and disease outcome of viral encephalitis in mice. Antiviral Res 2007, 75:104-112.

44. Zanoni G, Navone R, Lunardi C, Tridente G, Bason C, Sivori S, Beri R, Dolcino M, Valletta E, Corrocher R, Puccetti A: In celiac disease, a subset of autoantibodies against transglutaminase binds toll-like receptor 4 and induces activation of monocytes. PLoS Med 2006, 3:e358.

45. Bataller L, Kleopa KA, Wu GF, Rossi JE, Rosenfeld MR, Dalmau J: Autoimmune limbic encephalitis in 39 patients: immunophenotypes and outcomes. J Neurol Neurosurg Psychiatry 2007, 78:381-385.

46. Grigoriadis N, Hadjigeorgiou GM: Virus-mediated autoimmunity in Multiple Sclerosis. J Autoimmune Dis 2006, 3:1.

47. Sloka S: Observations on recent studies showing increased cooccurrence of autoimmune diseases. J Autoimmun 2002, 18:251-257.

48. Seissler J, de Sonnaville JJ, Morgenthaler NG, Steinbrenner H, Glawe D, Khoo-Morgenthaler UY, Lan MS, Notkins AL, Heine RJ, Scherbaum WA: Immunological heterogeneity in type I diabetes: presence of distinct autoantibody patterns in patients with acute onset and slowly progressive disease. Diabetologia 1998, 41:891-897.

49. Lin YC, Wu CN, Shih SR, Ho MS: Characterization of a Vero cell-adapted virulent strain of enterovirus 71 suitable for use as a vaccine candidate. Vaccine 2002, 20:2485-2493

50. Lin JY, Shih SR, Pan M, Li C, Lue CF, Stollar V, Li ML: hnRNP A1 interacts with the $5^{\prime}$ untranslated regions of enterovirus 71 and Sindbis virus RNA and is required for viral replication. J Virol 2009, 83:6106-6114.

51. He YQ, Yang H, Li LL, Tan J, Zhou L, Mao LS, Yang F, Liu JJ, Lv X: Genotype analysis of enterovirus type 71 detected from patients with hand-footmouth disease in Shenzhen. Zhonghua Liu Xing Bing Xue Za Zhi 2008, 29:790-793.

52. Bradford MM: A rapid and sensitive method for the quantitation of microgram quantities of protein utilizing the principle of protein-dye binding. Anal Biochem 1976, 72:248-254.

53. Arita M, Ami Y, Wakita T, Shimizu H: Cooperative effect of the attenuation determinants derived from poliovirus sabin 1 strain is essential for attenuation of enterovirus 71 in the NOD/SCID mouse infection model. $\int$ Virol 2008, 82:1787-1797.

54. Ito $W$, Kurosawa $Y$ : Development of an artificial antibody system with multiple valency using an Fv fragment fused to a fragment of protein A. J Biol Chem 1993, 268:20668-20675.

doi:10.1186/1743-422X-7-47

Cite this article as: Jia et al:: The cross-reactivity of the enterovirus 71 to human brain tissue and identification of the cross-reactivity related fragments. Virology Journal 2010 7:47. 